\title{
Historical Origins of Landscape Painting and Chinese Gardens
}

\author{
Chuan Wang \\ Department of computer and information technology \\ Boustead College, Tianjin University of Commerce \\ Tianjin 300384, China
}

Tel: 86-22-2759-9120Ｅ-mail: moffee1982@126.com

\begin{abstract}
Ancient Chinese landscape painting and landscape garden have very close historical ties. Knowing the relationship helps us to further understand the development process of the two. By analyzing relatively independent dynasties, this text expounds in detail the process of their birth, growth, prosperity and mutual influence, which helps to clarify the context of their development and understand the inevitable occurrence of some relevant historical trends.
\end{abstract}

Keywords: Landscape painting, Landscape garden, History, Context, Development

Chinese landscape painting and Chinese landscape garden, as a part of Chinese social and cultural life, are supported and controlled by the overall culture of Chinese society (the total of the material and spiritual civilization created in Chinese historical practice). Only after understanding the historical process of the social development and overall culture, can we have the opinion of some inevitability of the creation and development of the two artistic forms. As an artist or a designer, not knowing the cultural context, his artistic ideas and design concepts will be discountable due to lack of cultural inheritance and logic thinking. Only by constantly exploring the law of synchronous progress of the two artistic forms, can he or she be free to go into the kingdom of art.

\section{Rudimentary period of Qin and Han Dynasty}

Chinese garden art has a long history and can be traced back to ancient times. So far it has been three thousand years since the earliest recorded in history of Lingyu of West Zhou Dynasty in $11^{\text {th }}$ century before Christ, which was a place for the ancient emperors and noble people for hunting and recreation. A garden for recreation can cost a considerable manpower and resources. Therefore, only when a society develops to a certain degree, can the garden be likely to be constructed. After Qin kingdom conquered the other six kingdoms, it set up the Sanglin Garden on the south bank of Wei River, which spread to hundreds of Chinese Li. In the Western Han Dynasty, it was further expanded on the basis of Qin's scale so that a vast area to the south of Chang'an city belonged to emperor Wu. During his period, Shanlin Garden was expanded again and man-made mountains of Penglai, Fangzhang, Yingzhou were put in the garden to symbolize the holy mountains in East Sea. And the style of building gardens by simulating sea fairy realm has gradually become the basic model of managing water in Chinese gardens. It even has produced considerable impact on Japanese gardens. In the late East Han Dynasty, the garden patterns tended to be casual, and gradually turned to a freer layout instead of the symmetric way. Meanwhile, a new form of architectural modeling began to emerge.

By then, landscape painting, as a painting genre, had not got independent of the ancient art of painting yet. It was merely treaded as the background or context for dealing with the figure of story paintings of some artifacts or rock carvings. However, due to the admiration for the natural landscape, consciousness of inner cultivation with mountains as morality and water as temper or character had began to germinate and became the main line of Chinese landscape painting.

\section{Period of establishment-Wei Dynasty, Jin Dynasty, North and South Dynasties}

In the period of Wei Dynasty, Jin Dynasty, North and South Dynasties, there appeared intense competition or struggles among the ruling class, and the kingdoms were completely in chaos and the society was unrest. However, it was also the period full of comparatively free thoughts, rich wisdom and creative spirit in arts. The political instability and changeable life resulted in literati's pessimism. However, the migration of Jin court to the south made the intelligentsia and literati touch the beautiful landscape of the south China. They pursued the odd and enjoyed the places of interests. Enjoying the landscape and visiting the most famous places became the indispensable part of life of literate strata. Some 
even spent the whole life in nature, never regretted to end their life in the wild life. At the same time, painters began to indulge themselves in nature, copied the landscape, solitarily enjoying themselves to their heart desire. And the landscape paintings with expressing natural taste as the theme finally got rid of being taken as the background of figure paintings, and became an artistic genre and began to grow. According to historical records, in and after Liu Song court of the South Dynasty, some landscape painters such as Zongbing, Wang Hui, etc, specialized in landscape painting, had gradually turned up. At the same time, because people loved and admired nature, gardening art of this period has also been got enough developed. At that time, building gardens became fashionable. Particularly, such private gardens had also been developed considerably, as Zhang Wei's Hualin Garden in North Wei Dynasty, Shi Chong's Jingu Garden in West Jin Dynasty, etc. Although these private gardens in artistic grandeur were no better than those royal gardens, according to records, the beauty of natural landscape could be praised more than enough. At the same time, with the introduction of Buddhism, temple garden as a new form began to appear and achieved localization. It can be said that in both quantity and quality, landscape paintings and landscape gardens had already been set up as a separate form of artistic expression.

\section{Development period-Tang, Song and Yuan Dynasties}

After nearly 300 years of turmoil, political regime got reunited in Sui and Tang Dynasties. Because economy was recovered faster, cities and royal court buildings also began to develop. Emperor Wen of Sui Dynasty had Guangdaxingyuan built in Daxing city. Later, Emperor Yang had West Garden set up in his east capital of Luoyang. Private gardens in Tang Dynasty were in boom too. Nobles and officials had their gardens built within the capital, most of which were concentrated in the southeastern Qujiang area. In addition, there were many private gardens in the capital's eastern and the southern suburbs. The east capital Luoyang, as the provisional capital, was also the place for nobles and high officials to build parks or gardens. Tang Dynasty's natural landscape parks have also been developed. Good cases in point are Wang Wei's "Wangchuan Villa", and Bai Juyi's cottage in Lushan Mountain. Both were manually built in the context of the scenes in the natural scenic spots.

In the early Tang Dynasty, landscape painting developed slowly. It was only after the prosperous period of Tang Dynasty that it grew at a great leap and there appeared such famous painters as Li Sixun, Li Zhaodao, Wang Wei, etc. Realistic traits and creativity of landscape painting was greatly enhanced and continuous progress was made in techniques. A variety of styles and genres began to emerge. Ink Landscape painting and colored landscape began to go completely different way. In particular, the ink landscape attracted more and more eyeballs for its aesthetic value and began to develop independently to become prosperous.

The separation state in the period of Five Dynasties and Ten Kingdoms greatly destroyed society and economy, which made some southern cities become the centers of politics, handicrafts and business. For example, Suzhou, a place in Wu and Yue Kingdoms was one of the cities where building gardens was in a great fashion. In addition, Guangzhou, far in the south China also had built a number of gardens. Landscape painting in Five Dynasties and Ten Kingdoms got further improved on the basis of what had achieved in middle and later Tang Dynasty. Jing Hao, Guang Tong, Dong Yuan and other great artists appeared one after another, which indicated that ink landscape painting went into an unprecedented golden age of art. Artistically, it deeply tapped the emotional implication of nature and arrived at the realistic realm owing to great painter's creative techniques.

Song Dynasty ended the separation state of Five Dynasties and Ten Kingdoms. The ruling class people were more voluptuous and pleasure-seeking, so more gardens were built. Song gardens were more concentrated in Bianliang, the east capital, and Luoyang, the west capital. Royal gardens were mostly in Bianliang, the capital of the North Song Dynasty. Luoyang, the west capital of Song Dynasty had smaller number of gardens compared with Bianliang. Actually, they were still in considerable amount. In the famous picture of "Noted Gardens in Luoyang" painted by Li Gefei, it was recorded that there was more than twenty four royal gardens. Officials of Song Dynasty had especially strong sense of natural landscape. Seeking pleasure in landscape paintings became a universal psychological tendency. Apart from enjoying the material life, indulged in natural scenes and traveling became fashionable for the bureaucrats, the gentry, common landlords and scholars. Therefore, the landscape paintings reflecting natural beauty became unprecedented prosperous. The landscape painting of Song Dynasty had developed to a high degree of maturity. Its techniques were constantly enriched and the style became more diversified. In a word, the artistic achievement has surpassed the previous generations. As what Song people remarked, "techniques of landscape paintings in Song Dynasty was the best in history".

After Yuan Dynasty conquered the South Song Dynasty, China began to be ruled by foreigners. Ethnic and class contradictions were getting fiercer. As economy was in stagnation, little progress was made in garden construction. In addition that the rulers changed Jindaning Palace into Taiye Pool and Wansui Hill and made it the forbidden garden of the royal palace, there were few other activities of building gardens. There were a small number of private gardens in Dadou, that is, Beijing, capital of Yuan Dynasty. Compared with the decline of the garden architecture, there emerged some new changes in the ink landscape paintings due to the political and ideological pluralism. As to the traditional 
succession, there are two sources of systems. One is mainly from Mr. Dong and Mr. Ju of the Five Dynasties and the other is after Mr. Li and Mr. Guo of North Song Dynasty. There are a small handful of non-literati painters who pursue the tradition of Mr. Ma and Mr. Xia of South Song Dynasty.

\section{Mature period-the Ming and Qing Dynasties}

During 270 years of reign by the Ming Dynasty, due to the economic recovery and development, garden and garden architecture got new growth. Nanjing was the capital of the early Ming Dynasty. Emperor Chengzu moved his capital to Beijing and began to rebuild the city. And Taiye Pool was opened up to the south and formed into three lakes, the North Sea, the Middle Sea and the South Sea. It was considered to be the principal royal garden with the name of West Garden. By the middle period of the Ming Dynasty, due to the faster development of agriculture and handicraft industry, gardening became popular again. In this period, building gardens were mainly concentrated in Beijing, Nanjing and Suzhou. Suzhou at that time was a common city but it had very developed agriculture and handicraft industry, thus it was the richest economically. Many landlords and bureaucrats built their private houses and gardens there, which once came to a climax of garden construction. Many of the existing gardens, such as Zhuozheng Garden, Liu Garden, etc. were initially built during this period. Because of the political unity of the early Ming Dynasty, the painting aesthetic standard tended to be normalized. In artistic practice, it stressed the tradition, abided by the established rules or regulations, and allowed integration and imitation to pursue re-prosperity, expansion and reform in the rigid inheritance. Painters' artistic pursuit in their creation reflects their intent by systematically integrating the previous cultural achievements and re-displaying the essence of traditional techniques at the contemporary times. After the middle period of the Ming Dynasty, with economic development in the south of China, the artistic school of Wu Daozi was dominant in the field, which changed the phenomenon that narrative paintings were more than creative paintings. And some unique painters emerged. Particularly, a lot of different forms were derived from the ink painting style and techniques. At the same time the ink painting began to suit both the refined and popular tastes.

After the Ming Dynasty, building gardens in the Qing Dynasty obtained considerable development and arrived at climax in the Kangxi and Qianlong period. There were no less than ten royal gardens of Qing Dynasty in Beijing. Within the city gardens were further rebuilt or repaired on the basis of West Garden of the Ming Dynasty and more buildings were added to make it perfect. Royal gardens of the Qing Dynasty were more in number and larger in scale than those of the Ming Dynasty. Qing Dynasty is the most prosperous period in history of garden building. Private gardens were more in cities of Yangzhou, Suzhou, Wuxing, Hangzhou and the Pearl River Delta as well. Emperor Qianlong once on his way of tour to the south passed Yangzhou. At that time gardens of local officials could be seen along both sides of road from the Slender West Lake area to Pingshantang. Meanwhile, Suzhou also had a number of gardens built or rebuilt. According to statistics, there were more than 100 gardens of different sizes left in the early period of new China. Those still retained intact belong to the Late Qing Dynasty. As to the landscape painting, after the Yuan Dynasty, trend of thought about literati painting was in flood and fine brushwork of landscape painting was neglected by the expert artistic form. Jiehua was considered to be worldly or even vulgar and had low status in painting. As a result, fewer and fewer people worked on it. In the period of Kangxi and Qianlong of the Qing Dynasty, some painters were reluctant to be controlled by the trend at that time. Regardless the bad reputation they would have, they tried their best to save the fine brushwork of landscape painting and Jiehua out of the artistic dilemma to open a new situation. They made different contributions to the continuation and development of traditional art, but they could not get attention from the scholar-bureaucrat and their achievements were almost submerged by the strong literati paintings.

\section{Conclusion}

Hegel, a great German philosopher, once said, "all arts belong to a certain time and a certain nation, has their special context and depends on a certain history and the concept and destination". Chinese nation, in the process of long historical development, relying on this piece of vast land, abundant in resources and rich in fertile soil with various landscape scenes, has gradually formed the social phenomena and ideology with Chinese native features, the unique and complete universal outlook, world view, concept of values and cultural view which restrict and influence one another. Influenced by them, Chinese arts with the features of Chinese culture, such as Chinese landscape painting and classical Chinese landscape garden, begin to grow in the fertile soil of Chinese culture. Just like two different flowers on a vine, they have developed to be the first in the world with their dazzling brilliance in their respective field and produced a very far-reaching impact on the arts all over the world.

\section{References}

Chen, Zhi. (2006.08). History of Chinese garden construction. China Architecture and Building press.

Yu, Jianhua. (1957). Chinese painting in classification. People's Fine Arts Publishing House.

Zhang, Qiang. (2005.02). China's landscape painting. Henan Fine Arts Publishing House.

Zhou, Weiquan. (1990). History of Chinese classical gardens. Tsinghua University Press. 